\title{
Bioflavonoid Robinin from Astragalus falcatus Lam. Mildly Improves the Effect of Metothrexate in Rats with Adjuvant Arthritis
}

\author{
Lia Tsiklauri ${ }^{1}{ }^{1}$, Karol Švík ${ }^{2}$, Martin Chrastina ${ }^{2,3}$, Silvester Poništ ${ }^{2}$, František Dráfi ${ }^{2}{ }^{\circledR}$, Lukáš Slovák ${ }^{2}$, \\ Mery Alania ${ }^{1}$, Ether Kemertelidze ${ }^{1}$ and Katarina Bauerova ${ }^{2, *}$ \\ 1 Iovel Kutateladze Pharmacochemistry Institute, Tbilisi State Medical University, P. Sarajishvilist 36, \\ Tbilisi 0159, Georgia; l.tsiklauri@tsmu.edu (L.T.); m.alania@tsmu.edu (M.A.); e.kemertelidze@tsmu.edu (E.K.) \\ 2 Centre of Experimental Medicine, Institute of Experimental Pharmacology and Toxicology, \\ Slovak Academy of Sciences, Dúbravská cesta 9, 84104 Bratislava, Slovakia; karol.svik@savba.sk (K.Š.); \\ martin.chrastina@savba.sk (M.C.); silvester.ponist@savba.sk (S.P.); frantisek.drafi@savba.sk (F.D.); \\ lukas.slovak@savba.sk (L.S.) \\ 3 Jessenius Faculty of Medicine in Martin, Malá Hora 4A, 03601 Martin, Slovakia \\ * Correspondence: katarina.bauerova@savba.sk; Tel.:+421-2-32295731
}

check for updates

Citation: Tsiklauri, L.; Švík, K.; Chrastina, M.; Poništ, S.; Dráfi, F.; Slovák, L.; Alania, M.; Kemertelidze, E.; Bauerova, K. Bioflavonoid Robinin from Astragalus falcatus Lam. Mildly Improves the Effect of Metothrexate in Rats with Adjuvant Arthritis. Nutrients 2021, 13, 1268. https:// doi.org/10.3390/nu13041268

Academic Editor: Přemysl Mladěnka

Received: 26 February 2021

Accepted: 10 April 2021

Published: 13 April 2021

Publisher's Note: MDPI stays neutral with regard to jurisdictional claims in published maps and institutional affiliations.

Copyright: (c) 2021 by the authors. Licensee MDPI, Basel, Switzerland. This article is an open access article distributed under the terms and conditions of the Creative Commons Attribution (CC BY) license (https:/ / creativecommons.org/licenses/by/ $4.0 /)$.

\begin{abstract}
Anti-inflammatory potential of orally administrated bioflavonoid-robinin, active sub-stance of original drug Flaroninum ${ }^{\mathrm{TM}}$ (FL), was investigated in the combination with methotrexate (MTX) and in monotherapy in rats suffering from adjuvant-induced arthritis (AA). Robinin (kaempferol3-O-robinoside-7-O-rhamnoside) was isolated from the aerial parts of Astragalus falcatus Lam. The monotherapy with robinin was not efficient in alleviating symptoms of AA. The combination of MTX with robinin was similarly active as MTX alone in reducing the hind paw volume and change of body weight during the whole experiment. The combination, however, reduced plasma levels of Interleukin-17Aand activity of gamma-glutamyl transferase in joint more efficiently then MTX alone. Our results demonstrate that the novel combination of robinin and MTX mildly improved the reduction of inflammation in experimental arthritis.
\end{abstract}

Keywords: arthritis; flavonoids; robinin; methotrexate; astragalus

\section{Introduction}

Rheumatoid arthritis (RA) is an autoimmune inflammatory disease, which preferably targets the synovial joints and is associated with premature mortality and socioeconomic burdens [1]. The pathogenesis of RA is not fully understood yet, it is suggested that the abnormal activation of inflammatory signaling pathways, hormonal imbalance, smoking, and oxidative stress play significant roles in the development of RA [2]. Current treatment strategies for RA are based on the aim to control disease activity, lower structural damages, and enhance quality of life. In addition to conventional disease-modifying antirheumatic drugs (DMARDs), that are particularly associated with different side effects, targeted DMARDs are more suitable for the treatment of RA [3,4]. Clinical studies showed that combinations of drugs are more effective than a single medicine alone for the management of inflammatory arthritis. Methotrexate (MTX) is the first line drug in the treatment of rheumatoid arthritis [5]. Natural remedies became a significant field of interest for the development of newer medicines, because they are a rich source of different compounds with potentially novel mechanisms of action. Indeed, anti-inflammatory phytomolecules were shown to possess a wide scale mechanism of action including interactions with the inflammatory pathways [6,7]. Robinin belongs to flavonoids, which are an essential group of naturally occurring polyphenolic compounds, widely distributed in the plant kingdom and exhibiting vast range of beneficial biological activities, including antiphlogistic (antiinflammatory) action. These effects may interact directly with pro-inflammatory signal 
proteins. Flavonoids may affect specifically the function of enzyme systems critically involved in the generation of inflammatory processes, especially tyrosine and serinethreonine protein kinases [8,9]. However, the use of these compounds in clinical praxis is modest due to their low bioavailability [10]. In our experiment, we selected the higher dose of robinin from our pilot study with robinin applied in two doses (unpublished results) to partially compensate it's low bioavailability.

Robinin is found in plants of the genus Astragalus which is broadly distributed throughout the temperate and arid regions and known to contain phytochemicals, which are found in most parts of the plant and have been associated with multiple actions i.e., antiinflammatory, pain relieving and protective effects [11,12]. Astragalus falcatus Lam. is widely distributed in Georgia. This plant has been intensively investigated at the I. Kutateladze Pharmacochemistry Institute (IKPI) of the Tbilisi State Medical University (TSMU) and hypoazotemic flavonoid glycoside robinin was isolated from its aerial parts $[13,14]$. Based on this compound, the original preparation Flaroninum ${ }^{\mathrm{TM}}(\mathrm{FL})$ in the form of tablets has been proposed [14]. FL has been approved as a drug by the Georgian and Russian healthcare authorities. This medicine possess diuretic and hypotensive effects. The active substance of this product is robinin, which is one of the derivatives of kaempferol (Figure 1). This substance has been isolated also from plants Pueraria hirsuta (Thunb.) Matsun. and Astragalus sp. $[15,16]$. The bioflavonoid robinin (RB) exerts anti-inflammatory and strong antioxidant activities. Eom et al. [17] have reported Kudzu leaf extract, with main constituent robinin, reduced the expression of inducible nitric oxide synthase, cyclooxygenase-2, interleukin- 6 , and tumor necrosis factor- $\alpha$. Robinin therapeutically improved lipid peroxidation in heart tissue and inflammatory markers, cyclooxygenase-2 and lipoxygenase-15 and reduced cardiotoxicity by modulating transforming growth factor beta 1signaling pathway in Sprague Dawley rats [18]. Robinin inhibited the oxidized low-density lipoprotein (LDL) lipoprotein (ox-LDL) induced toll-like receptors 2 (TLR2) and toll-like receptors 4 (TLR4) expression and inhibited the translocation of nuclear factor kappa B (NF-kB) p65 by modulating the TLR-NF-KB signaling pathway [19]. In this study, we examined the potential antiinflammatory properties of orally administrated robinin in the experimentally-induced arthritis in monotherapy and in combination therapy with MTX. In this context, we used rat adjuvant induced arthritis (AA) model: This well-known model is T-lymphocyte dependent and is associated with hyperplasia of the synovium and inflammation in joints [20,21].

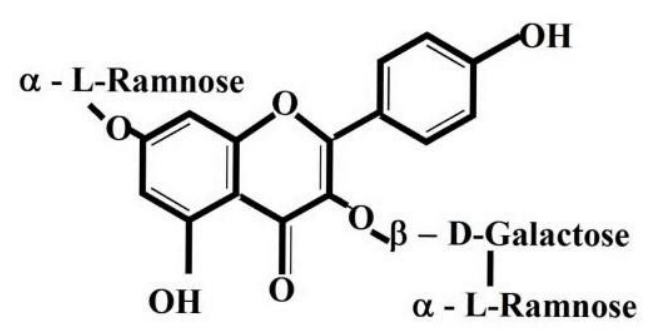

Figure 1. Chemical structure of kaempferol 3-O-robinoside-7-O-rhamnoside (robinin (RB)).

\section{Materials and Methods}

Flavonoid glycoside robinin ( $\geq 95 \%)$ was isolated at IKPI. Flowers and leaves of $A s-$ tragalus falcatus Lam. were collected from Didi Toneti, Kartli floristic region, Georgia, and identified by botanists of Pharmacobotany, Department of Phytochemistry of IKPI. Voucher specimens (N 16354) were deposited at the herbarium collection of IKPI (Herbarium CodeTBPH). Air dried and crushed aerial parts (leaves and flowers) $(10 \mathrm{~kg}$ ) of Astragalus falcatus Lam. were extracted with $70 \%$ ethanol three times (raw material:solvent, 1:10, w/v; at room temperature) by maceration for 3 days. The combined extracts were dried under low pressure (100-140 $\mathrm{mm} \mathrm{Hg}$ ) at $70-80{ }^{\circ} \mathrm{C}$ to obtain $15 \mathrm{~L}$ of aqueous residue. The remaining aqueous phase was filtered and treated with chloroform $(1 \mathrm{~L}) 3$ times to remove lipophilic compounds; then, a small volume of organic solvent (chloroform) was added and kept for $24 \mathrm{~h}$. Formed crystals were filtered, washed with ethanol (45\%), and air dried. This 
technical product was recrystallized from diluted ethanol (45\%) and dried under vacuum at $70-80{ }^{\circ} \mathrm{C}$; the yield of obtained robinin was $1.72 \%$. The flavonoid content was analyzed by spectrophotometric method using aluminum chloride. In brief, the stock solution of robinin $(0.2 \%)$ was prepared in ethanol $(70 \%)$ by gentle heating. The work solution $(0.004 \%)$ was obtained by appropriate dilution of stock solution with $70 \%$ ethanol. $\mathrm{AlCl}_{3}$ solution $(5 \mathrm{~mL}, 0.5 \%, w / v)$ was added to $5 \mathrm{~mL}$ of this (or standard $0.004 \%$ ) solution and mixed. Then, after $10 \mathrm{~min}$ of incubation at room temperature, samples were subjected to spectral analysis. Absorbance measurements were performed on the spectrophotometer using $10 \mathrm{~mm}$ width cuvette against a blank solution (which contained equal volumes $(5 \mathrm{~mL})$ of ethanol $(70 \%)$ and aluminium chloride $(0.5 \%)$ solutions) at $390 \mathrm{~nm}$. The concentration of standard solution of robinin was $0.004 \%$. Robinin standard (99\% purity) was obtained in Phenolic Compounds, Department of Phytochemistry of IKPI. For this experiment, the stock suspension of tested compound was prepared on daily basis, as vehiculum redistilled water was used. The incomplete Freund's adjuvant (IFA) was obtained from MERCK (Sigma Aldrich, St. Louis, MO, USA) and heat-inactivated Mycobacterium butyricum (MB) was obtained from BD Difco ${ }^{\mathrm{TM}}$ (Sparks, MD, USA). Methotrexate (Ebewesol ${ }^{\circledR}$ inj. $20 \mathrm{mg} / \mathrm{mL}$ ), heparin (HEPARIN LÉČIVA ${ }^{\circledR}$ Praha, Czech Republic), tiletamine with zolazepam (Zoletil ${ }^{\circledR}$ 50, Virbac, Carros, France), and xylazine (Xylariem ${ }^{\circledR} 20 \mathrm{mg} / \mathrm{mL}$, ECUPHAR N.V., Oostkamp, Belgium) were used for this experiment. Chemicals for $\gamma$-glutamyltransferase (GGT): buffer $\left(2.6 \mathrm{mM} \mathrm{NaH}_{2} \mathrm{PO}_{4}, 50 \mathrm{mM}\right.$ of $\mathrm{Na}_{2} \mathrm{HPO}_{4}, 15 \mathrm{mM}$, ethylenediaminetetraacetic acid (EDTA), $68 \mathrm{mM} \mathrm{NaCl}$; pH 8.1), $8.7 \mathrm{mM} \mathrm{L-} \gamma$-glutamyl- $p$-nitroanilide, $44 \mathrm{mM}$ methionine, $65 \%$ isopropyl alcohol, methanol were obtained from MERCK (Sigma Aldrich, St. Louis, MO, USA).

\subsection{Laboratory Animals}

In this experiment Lewis male rats were purchased from Department of Toxicology and Laboratory Animal Breeding, Centre of Experimental Medicine, SAS, Dobrá Voda, Slovak Republic (SK CH 24016). Immediately after housing of animals, rat were submitted to a seven-day quarantine. Animals had unlimited access to standard diet and tap water ad libitum, as well as dark/light regime $12 \mathrm{~h} / 12 \mathrm{~h}$. The animal housing agrees with EU Convention for the Protection of Vertebrate Animals Used for Experimental and Other Purposes. The authorization of the protocol for this experiment was done by the Ethics Committee of the Institute of Experimental Pharmacology and Toxicology, Center of Experimental Medicine SAS in Bratislava, Slovakia (SK UCH 04018) and State Veterinary and Food Administration of the Slovak Republic, Bratislava (3144/16-221/3).

\subsection{Adjuvant Induced Arthritis in LEWIS Rats}

The AA is a well-established model of inflammation [20,21]. The adjuvant arthritis was induced in rats with weight of 160-180 g (6 weeks) by an individual intradermal immunization at the base of the tail with suspension of $0.1 \mathrm{~mL}$ of $12 \mathrm{mg} / \mathrm{mL}$ heat-inactivated MB powder suspended in incomplete IFA according to our previous protocol $[22,23]$.

\subsection{Treatments and Design of Experiment}

The animals were assigned to 5 groups of eight rats in each. Group one was used as healthy controls. The second was untreated AA group. The remaining three groups were AA rats treated as given in the study design below (Table 1).

The tested substance and MTX were administered orally (via gastric tube) during the whole experiment (28 days); RB was partially dissolved in tap water and administered daily; anti-rheumatic drug-MTX was diluted with tap water and applied two times a week in dosage of $0.3 \mathrm{mg} / \mathrm{kg}$ of b.w. The b.w. of animals was measured before administration of tested substances. On days 14 and 21, the blood was withdrawn into heparanized tubes from the rat's retro-orbital plexus using tiletaminum, zolazepamum plus xylazine anesthesia. On the last experimental day, rats were sacrificed in anesthesia, the blood was obtained, and tissues (spleen and hind paw joint) were collected from all animals. Blood 
samples were centrifugated at $2000 \times g$ for $15 \mathrm{~min}$. This procedure depletes the platelets from the samples of plasma. Samples were saved under $-70{ }^{\circ} \mathrm{C}$.

Table 1. Experimental design.

\begin{tabular}{ccc}
\hline Group & Treatment and Active Substance & Posology \\
\hline Group 1: Healthy controls (CO) & vehiculum & $0.5 \mathrm{~mL}$ \\
\hline Group 2: AA untreated & vehiculum & $0.5 \mathrm{~mL}$ \\
\hline Group 3: AA + treatment & Methotrexate (MTX) & $0.3 \mathrm{mg} / \mathrm{kg}$ of b.w. twice a week \\
\hline Group 4: AA + treatment & Robinin (RB) & $50 \mathrm{mg} / \mathrm{kg}$ of b.w. daily \\
\hline Group 5: AA + treatment & Robinin+MTX (RB-MTX) & $50 \mathrm{mg} / \mathrm{kg}+\begin{array}{c}0.3 \mathrm{mg} / \mathrm{kg} \text { of b.w. twice } \\
\text { a week }\end{array}$ \\
\hline
\end{tabular}

AA—adjuvant arthritis, MTX—methotrexate, b.w.—body weight.

\subsection{Evaluation of Experimental Arthritis}

On the day 14th, 21st, and 28th after immunization of the animals, the hind paw joints were assessed. Hind paw volume (HPV) was expressed as the average of the elevation of percentage (\%) of the hind paw volume of every rat, compared with HPV measured at day 1 using a water plethysmometer (UGO BASILE, Comerio-Varese, Italy). The HPV on the selected day was divided by the HPV on day 1 and expressed in per cent according to the following formula w: ([n Day]/[Day 1]) $\times 100-100=$ value [\%] The body weight of the animals was measured daily. The changes in body weight are shown as average of the weight gain [g]. Weight measured on the day (n-day 14, 21 and 28) minus weight measured on day 1 . The mathematical formula we used is as follows: [n Day $]-[$ Day 1$]$ = value $[g]$.

\subsection{The Activity of $\gamma$-Glutamyltransferase in the Hind Paw Joint and Spleen Tissue}

The cellular activity of $\gamma$-glutamyltransferase (GGT) was measured on day 28 in the spleen and hind paw joint tissue homogenates using the method of Orlowski and Meister [24] and modified by Ondrejickova et al. [25]. The tissues were homogenized in a buffer ( $2.6 \mathrm{mM}$ of $\mathrm{NaH}_{2} \mathrm{PO}_{4}, 50 \mathrm{mM}$ of $\mathrm{Na}_{2} \mathrm{HPO}_{4}, 68 \mathrm{mM}$ of NaCl,15 mM of EDTA; pH $8.1)$ at $1: 9(w / v)$ by Ultra Turax TP $18 / 10$ (Janke and Kunkel) for one min at $0{ }^{\circ} \mathrm{C}$. The biochemical substrates ( $44 \mathrm{mM}$ of methionine and $8.7 \mathrm{mM}$ of L- $\gamma$-glutamyl- $p$-nitroanilide) were dissolved in isopropyl alcohol $(65 \%)$ to final concentrations of $2.5 \mathrm{mM}$ and $12.6 \mathrm{mM}$, respectively. After one hour incubation at $37^{\circ} \mathrm{C}$, the reaction was stopped by adding $2.3 \mathrm{~mL}$ of cold methanol. Tubes were centrifuged at $5000 \mathrm{rpm}$ for $20 \mathrm{~min}$ (Centrifuge Eppendorf). Supernatant's absorbance (product $p$-nitroaniline) was determined on spectrophotometer Specord 40 at $406 \mathrm{~nm}$. Solution mix without or without substrate or acceptor were used as blanks.

$\mathrm{a}=\frac{\mathrm{A}}{\mathrm{k}} \times \frac{3.2}{0.5} \times \frac{1}{13,813} \times \frac{1000}{\text { tissue }[\mathrm{mg}]} \times \frac{1}{60} \times 1000[\mathrm{nmol} \mathrm{p}-$ nitroaniline $/ \mathrm{min} /$ gtissue $]$.

Mathematical formula explanatory note:

A-absorbance;

c-concentration of p-nitroaniline $[\mu \mathrm{g} / \mathrm{mL}]$;

$\mathrm{k}$-coefficient from calibration curve $\mathrm{A}=\mathrm{k}$. c.

\subsection{Levels of Interleukin $17 \mathrm{~A}$ in Plasma Samples}

The level of plasmatic Interleukin-17A (IL-17A) was determined using an enzymelinked immunosorbent assay type kit (eBioscience ${ }^{\circledR}$; Waltham, MA, USA) according to the instruction of the manufacturer. Statistical analyses. The average values \pm SEM were calculated. Significant differences between control animals, untreated animals, and treated groups of animals were determined by ANOVA. The post hoc test (Tukey-Kramer) was applied in cases where differences between groups was significant. The levels of signif- 
icance after the post hoc screening were specified as followed: not significant $(p>0.05)$, significant $(p \leq 0.05)$, very significant $(p \leq 0.01)$, and highly significant $(p \leq 0.001)$.

\section{Results}

\subsection{Change of the Body Weight (CBW)}

AA animals have significantly lower weight gains in comparison to the controls. This effect was observed within the duration of the whole experiment. RB had no effect on this parameter at any analyzed day. MTX alone was partly active at day 14 and 21. Similarly, the combination decreased the loss of weight versus the control group at the same days. At the end of the experiment, however, none of the treatment significantly modified this parameter (Figure 2).

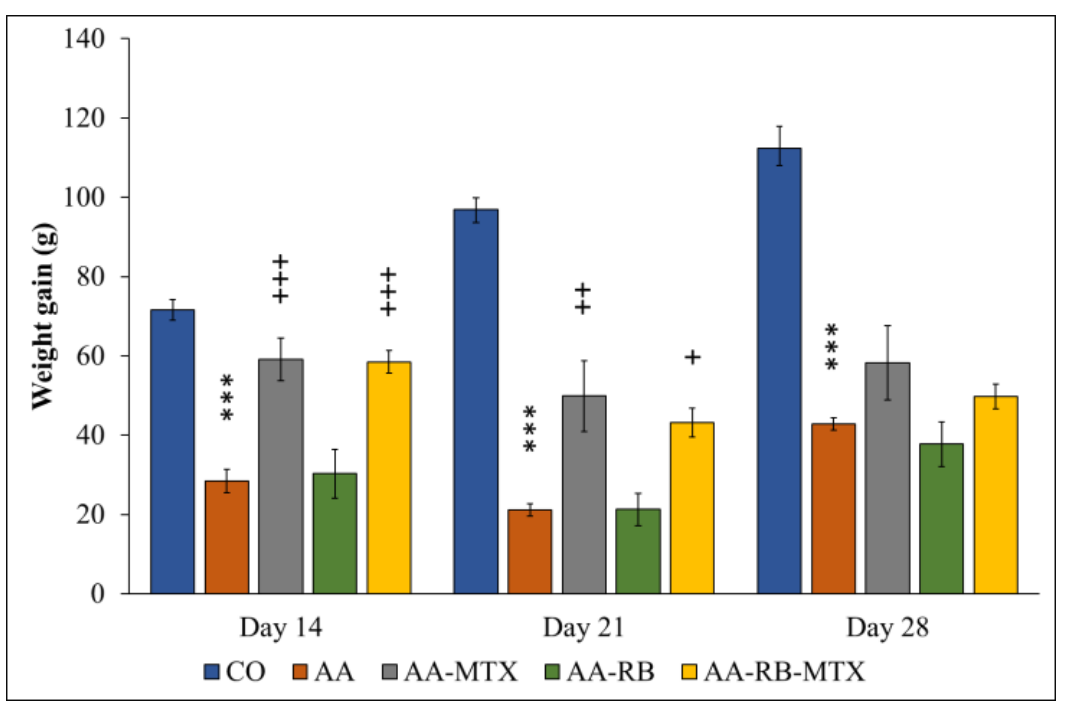

Figure 2. The effect of RB administered alone or in combination with MTX on the change of the body weight on days 14, 21 and 28. CO-control animals, AA—adjuvant arthritis controls, AA-MTXadjuvant arthritis group treated with methotrexate $0.3 \mathrm{mg} / \mathrm{kg}$ of b.w. twice a week, AA-RB — adjuvant arthritic animals treated by RB in dosage of $50 \mathrm{mg} / \mathrm{kg}$, AA-RB-MTX_adjuvant arthritic animals treated with RB (50 mg/ kg) and $0.3 \mathrm{mg} / \mathrm{kg}$ of b.w. twice a week. Results were expressed as mean $\pm \mathrm{SEM}, n=8$. Significant difference: ${ }^{* * *} p<0.001$ AA vs. CO, $+++p<0.001$ treated groups vs. $\mathrm{AA},++p<0.01$ treated groups vs. AA, $+p<0.05$ treated groups vs. AA. Weight measured on the day (n-day 14, 21, and 28) minus weight measured on day 1 . The mathematical formula we used is as follows: $[\mathrm{n}$ Day] $-[$ Day 1$]=$ value $[\mathrm{g}]$.

Hind Paw Volume (HPV)

Hind paw swelling is a consequence of inflammatory, as well as arthritic, changes occurring in AA rats. AA animals have significantly higher hind paw volumes in comparison to the controls (Figure 3). This effect was observed within the duration of the whole experiment. RB had no effect on HPV at any day measured. MTX alone was significantly active in reduction of HPV at day 14. However, on days 21 and 28, the effect of MTX was only partial. Similar trend was observed with the combination being significantly active in reduction of HPV at day 14, but, on days 21 and 28, only moderate effect was measured (Figure 3). 


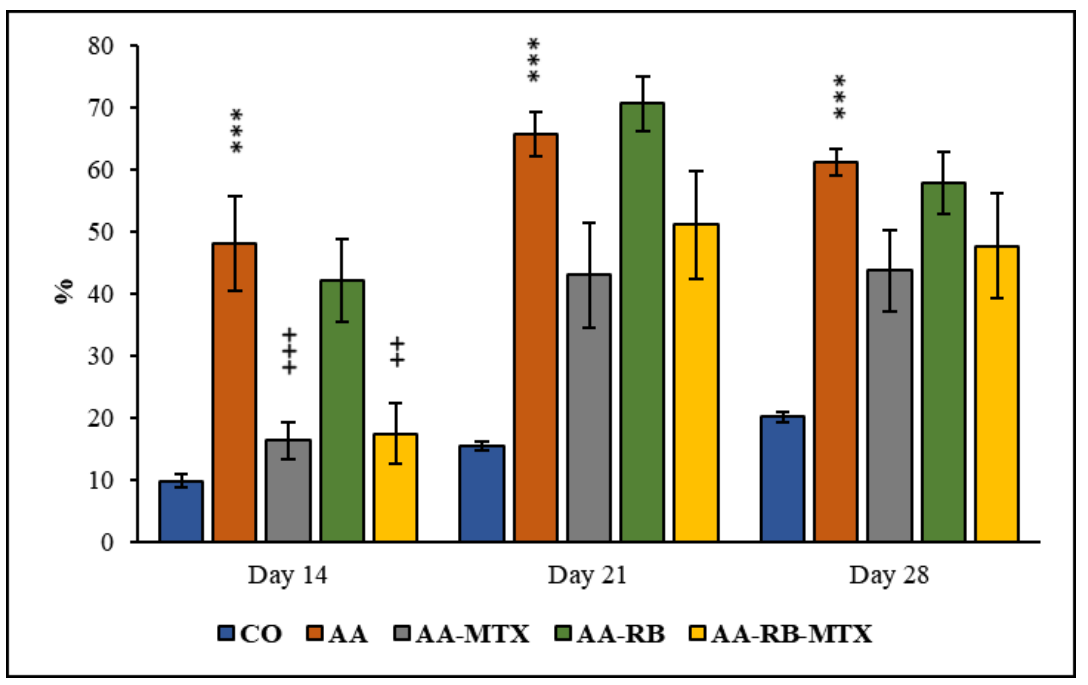

Figure 3. The effect of RB administered alone or in combination with MTX on hind paw volume (HPV) on days 14, 21, and 28. CO—control animals, AA—adjuvant arthritis controls, AA-MTX—adjuvant arthritis group treated with methotrexate $0.3 \mathrm{mg} / \mathrm{kg}$ of b.w. twice a week, AA-RB-adjuvant arthritic animals treated by RB in dosage of $50 \mathrm{mg} / \mathrm{kg}$, AA-RB-MTX—adjuvant arthritic animals treated with $\mathrm{RB}(50 \mathrm{mg} / \mathrm{kg})$ and $0.3 \mathrm{mg} / \mathrm{kg}$ of b.w. twice a week. Results were expressed as mean $\pm \mathrm{SEM}, n=8$. Significant difference: ${ }^{* *} p<0.001$ AA vs. $\mathrm{CO},+++p<0.001$ treated group vs. AA, $++p<0.01$ treated group vs. AA. The HPV volume on the selected day (n-day 14, 21, and 28 ) is divided by the HPV volume on day 1 . All this is multiplied by 100 and, finally, minus 100, we get the percentage. The mathematical formula we used is as follows: ([n Day]/[Day 1]) $\times 100-100=$ value [\%].

\subsection{Activity of Cellular $\gamma$-Glutamyl-Transferase in the Hind Paw Joint and Spleen Tissue}

Differences in enzymatic activity of GGT in spleen and joint are shown on Figure 4 on day 28. GGT increased by $46 \%$ in joint and $250 \%$ in spleen compared with the healthy control group (Figure 4A). The MTX administration caused an insignificant reduction of GGT activity in both tissues. Application of RB did not influence, as well, the activity of GGT in both tissues (Figure 4A), but the combination of MB with MTX significantly reduced the activity of GGT in the hind paw joint but not in the spleen (Figure 4).

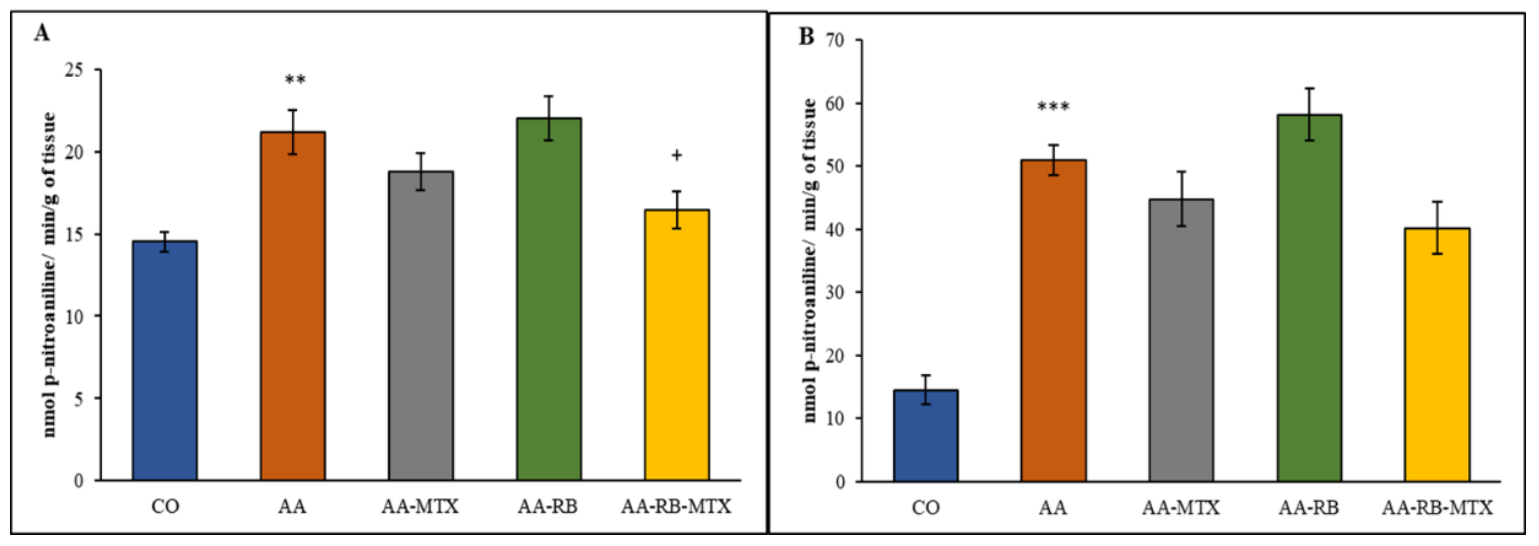

Figure 4. The effect of RB administered alone or in combination with MTX on the activity of GGT in joint (A), spleen (B) on day 28. CO—control animals, AA—adjuvant arthritis controls, AA-MTX—adjuvant arthritis group treated with methotrexate $0.3 \mathrm{mg} / \mathrm{kg}$ of b.w. twice a week, AA-RB—adjuvant arthritic animals treated by RB in dosage of $50 \mathrm{mg} / \mathrm{kg}$, AA-RB-MTX_adjuvant arthritic animals treated with RB (50 mg/kg) and $0.3 \mathrm{mg} / \mathrm{kg}$ of b.w. twice a week. Results were expressed as mean $\pm \mathrm{SEM}, n=8$. Significant difference: ${ }^{* *} p<0.001$ AA vs. CO; ${ }^{* *} p<0.01$ AA vs. CO, $+p<0.05$ treated group vs. AA. The activity of cellular $\gamma$-glutamyltransferase was calculated according to the formula already mentioned in Section 2.5 . 


\subsection{Interleukin-17A in Blood Plasma}

The concentrations of IL-17A in blood plasma were determined on experimental days 14,21 , and 28. In the model group (AA), IL-17A concentration were markedly enhanced at day 14 and then gradually dropped within the duration of the experiment and were only insignificantly higher at the end of the experiment. Only on day 14 in the MTX group did the plasma levels of this cytokine decrease significantly compared to AA group. The treatment of combination of RB-MTX group showed a significant decrease (Figure 5) in levels of this cytokine on days 14 and 21 when compared to untreated AA rats. Additionally, plasma levels of IL-17A in the combination group of RB-MTX were decreased by $42.6 \%$ and $12.7 \%$ more efficiently, when compared to MTX monotherapy on days 21 and 28 (Figure 5).

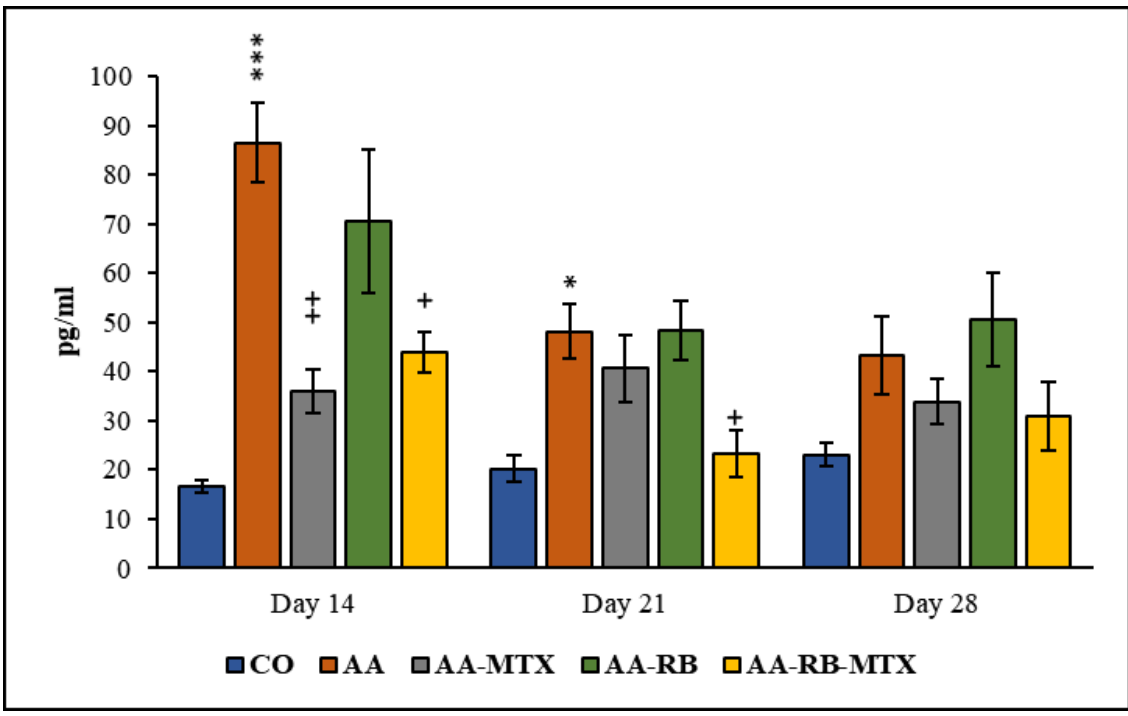

Figure 5. The effect of RB administered alone or in combination with MTX on the levels of IL-17A in blood plasma on days 14, 21, and 28. CO-control animals, AA—adjuvant arthritis controls, AA-MTX_adjuvant arthritis group treated with methotrexate $0.3 \mathrm{mg} / \mathrm{kg}$ of b.w. twice a week, AA-RB — adjuvant arthritic animals treated by RB in dosage of $50 \mathrm{mg} / \mathrm{kg}$, AA-RB-MTX—adjuvant arthritic animals treated with $\mathrm{RB}(50 \mathrm{mg} / \mathrm{kg})$ and $0.3 \mathrm{mg} / \mathrm{kg}$ of b.w. twice a week. Results were expressed as mean $\pm \mathrm{SEM}, n=8$. Significant difference: ${ }^{* * *} p<0.001$ vs. $\mathrm{CO},++p<0.01$ vs. AA, * $p<0.05$ vs. $\mathrm{CO},+p<0.05$ vs. AA.

\section{Discussion}

This is the first in vivo study, were the anti-inflammatory effect of the active substance robinin (RB) on the development of adjuvant arthritis (AA) was investigated. We have also examined the combined administration of RB with antirheumatic drug MTX. Adjuvant arthritis is recognized as one of extensively used animal model for studying the series of inflammatory processes that occur in RA and validating novel anti-inflammatory and anti-rheumatic drugs $[20,21,26,27]$. The key drugs for RA treatment are disease modifying anti-rheumatic drugs (DMARDs), including MTX. MTX is able to decrease synovial, as well as systemic, inflammatory processes, and it improves the function of joints [28,29]. To determine the effectiveness of the substance tested, MTX was chosen as the most commonly used drug in RA. In our previous studies, MTX has been proved as a good standard to examine the efficiency of experimental treatments [28]. Furthermore, MTX is the cornerstone in the therapy of RA either as a single drug or in combination with other drugs to maximize the therapeutic efficacy [30-32]. It is little known about the bioavailability of robinin. In previous studies we examined the possible involvement of membrane efflux transporter (P-glycoprotein) in oral absorption of this compound. According to the obtained results P-glycoprotein, located in the intestinal epithelial cells may be responsible for its low oral bioavailability [33]. Robinin is a very safe compound, 
its $\mathrm{LD}_{50}$ is higher than $>1 \mathrm{~g} / \mathrm{kg}$ in mice $[34,35]$. According to this acute toxicity study, a safe dose of $50 \mathrm{mg} / \mathrm{kg}$ of RB was selected for this experimental design.

AA animals have a quick onset and progression of disease with poly-articular inflammation, which is manifested by increased volume of the hind paw and a typical course of loss of body weight [36].

In all AA rats, the body weight gain was significantly lower than in control animals (Figure 2), which may be due to the alterations in the metabolic activities caused by systemic inflammation during AA [37]. Earlier findings suggested that major clinical markers, HPV and body weight gain, are remarkably worsened due to inflammation and were effectively diminished by administration of compounds with anti-oxidative and/or anti-inflammatory properties [38-40]. The protective effect of MTX against AA development agrees with previously reported results $[23,28,37,40,41]$ as well as with changes of HPV shown in Figure 3. Combination of RB with MTX did not improve these protective effect of MTX (Figures 2 and 3). Gamma-glutamyl transferase (GGT) is an enzyme found in cell surface of various tissues of the body and considered as one of the pathogenic factors involved in the inflammatory processes. Raised expression and activity of GGT in joint tissue is a good experimental standard for synovial inflammation in collagen-induced arthritis. It is thought that neutralization of GGT with anti-GGT antibody might be novel therapeutic agents for attenuating joint destruction in RA patients [42,43]. In this study, the GGT activity was higher in AA animals than in healthy controls in the spleen and in the joints homogenates (Figure 4). These data resemble the clinical studies of patients suffering RA with raised activity of GGT not only in the urine and serum, but in synovial fluid too [44]. The combination of MTX and RB had a significant effect in lowering the GGT activity in joints of animals (Figure 4A). The effectivity of MTX was marked also in studies with a similar setting and design of the experiment $[37,45]$. In earlier investigations, we demonstrated a positive agreement between the GGT activity in joint tissue and the hind paw volume of AA animals [46]. Correspondingly, as it is shown in Figure 4A, our previous results $[37,45,46]$ are also in a good agreement with the current observation in changes of HPV (Figure 3).

Suppressing cytokines with natural products has become an important focus in the development of new drugs to treat RA [47]. Inflammatory processes in RA, such as swelling of the synovium of the joint, with subsequent destruction of articular structures are associated with activation of synovial fibroblasts and Th-lymphocytes [48]. In the last few years, various studies figured out that the manifestation of RA is critically dependent on expression of TLR family members expression, which in turn is acknowledged to play a crucial role in T-lymphocytes function and differentiation [49-51]. Previous studies have shown the importance of TLR4 and TLR2 function in the pathogenesis of RA. Since the expression of these genes is increased and regulated by proinflammatory cytokines. Activation of TLRs intensifies T-helper lymphocytes (Th17) cell expansion in pro-inflammatory cytokine-dependent signaling, with increased accumulation of interleukin IL-17 [52,53]. IL17A is the key cytokine of the Th17 population and has been involved in the inflammatory processes of RA. Anti-IL-17 treatments could improve approaches to control the disease chronicity. Several studies have shown the increased concentration of IL-17A and/or Th17 in inflamed joints and blood of the patients suffering RA. It was recently shown a relation of IL-17A concentrations with the disease activity or joint damage [54,55]. Recent understanding of the etiopathogenesis of RA emphasized the role of the cytokine network in the initialization and development of the illness, which has bought a novel class of drugs for RA directly targeting cytokines [56]. Experimental, as well as clinical, proofs exhibit that IL-17A is a therapeutically appropriate target for RA interventions [57]. Multiple hypotheses, including alteration of cytokine profiles, have been proposed to explain the mechanism of MTX efficacy in RA [58]. MTX has been found to influence cytokine production and inhibits the up-regulations of IL-17A in the co-culture of T-cells and fibroblasts. Li et al. (2012) showed that MTX can suppress IL-17 production, which could support its anti-inflammatory activity in the therapy of RA [59]. Luo et al. [60] hypothesized that 
MTX may exert its therapeutic effect by inhibiting the expression of TLR2 and TLR4. The antioxidant and anti-inflammatory phytochemicals can be used as potential therapeutic agents for arthritis.

In our study, we examined the effect of RB on the plasma concentration of IL-17A during the development of AA. Recent works suggests that IL-17 contributes to RA chronicity and late pathogenic responses through synovial inflammation and hyperplasia [61].

This also applies for AA [62-64]. RB alone has no effect on the IL-17A levels in plasma (Figure 5). However, RB in combination with MTX decreased the IL-17A levels in plasma on days 14 and 21 significantly (Figure 5). Our previous results with fatsiphloginum, especially in combination with MTX, are comparable, with results from this study [41]. The anti-inflammatory activity of robinin could be explained also via its metabolites. Administration of robinin to rats resulted in the urinary excretion of kaempferol with smaller amounts of $p$-hydroxyphenylacetic acid. Formation of $p$-hydroxyphenylacetic acid was increased in animals that had previously received a diet containing kaempferol or robinin. The same metabolites were shown to be formed on incubation of robinin with the microflora [65]. The 3-flavonols kaempferol and robinin undergo a cleavage reaction analogous to that reported for quercetin, and these metabolites were reported to have biological activities [66]. Kaempferol as a major metabolite of robinin possesses also antiinflammatory effects. These might be responsible for anti-inflammatory effects observed after per oral administration of robinin, as well. The in vitro study of Lee et al. (2010) has shown that kaempferol has significantly inhibited cyclooxygenase 1 and 2 (COX2) reaction. Kaempferol and cytokines have been incubated with isolated human hepatocytes, and it was noted that COX2 and inducible NO-synthase levels were decreased [67]. Moreover, kaempferol also suppressed the release of IL-6, IL-1 $\beta$, IL-18, and TNF- $\alpha$ in lipopolysaccharide plus adenosine triphosphate-induced inflammatory response in cardiac fibroblasts [68]. Probably the beneficial anti-inflammatory activity of RB in combined with MTX might be due to the inhibition of the release of pro-inflammatory cytokines in joints of AA animals.

\section{Conclusions}

In this study, the anti-inflammatory and anti-arthritic activity of robinin (RB) was evaluated for the first time. RB in monotherapy was not efficient in reducing any of parameters measured. The beneficial properties of MTX monotherapy were not enhanced by the co-administration of RB on CBW and HPV. However, the combination of MTX-RB was more effective in decreasing the activity of GGT in the hind paw joint and in lowering the plasmatic level of IL-17A than MTX alone. However, further investigations on the mechanism of anti-inflammatory and anti-arthritic action, as well as the oral pharmacokinetic profile of RB, are needed for better understanding of robinin efficacy in RA. Importantly, $\mathrm{RB}$ is a very safe compound and, hence, potentially suitable for combination regimens.

Author Contributions: L.T. Performed the experiment; evaluation of results and substantially participated on manuscript preparation; approved the final version of the manuscript. M.A. Provided the active substance; revised the manuscript. E.K.; Academician: Revised the manuscript. K.B. Responsible for supervision of the experiment, project administration, funding acquisition and revision of the manuscript; approved the final version of the manuscript. S.P. Contributed to the design of the article; preparation of the first draft of the manuscript; responsible for data curation; substantially manuscript preparation; revised manuscript critically; contributed to the final version of the manuscript; approved the final version of the manuscript. F.D. Contributed to the design of the article; preparation of the first draft of the manuscript; responsible for data curation; revised manuscript critically; substantially manuscript preparation; contributed to the final version of the manuscript; approved the final version of the manuscript. M.C. Performed the statistical analysis of data and prepared figures. L.S. Prepared methodology and performed laboratory work. K.Š Prepared methodology and performed laboratory work. All authors have read and agreed to the published version of the manuscript. 
Funding: This research was supported by National Scholarship Program of the Slovak Republic (NSP), the grant was awarded to Lia TSIKLAURI, and supported by Slovak grant agency VEGA2/0136/20, VEGA 2/0115/19 and APVV-15-0308.

Institutional Review Board Statement: The study was conducted according to the guidelines of the Declaration of Helsinki and approved by the Institutional Ethics Committee the Institute of Experimental Pharmacology and Toxicology, Center of Experimental Medicine SAS in Bratislava, Slovakia (SK UCH 04018) and State Veterinary and Food Administration of the Slovak Republic, Bratislava (3144/16-221/3).

Informed Consent Statement: Not applicable (this study has not involved human volunteers).

Data Availability Statement: Data from this study are available here: https:/ / drive.google.com/ file/d/109aUyrDB3Fy62avxtc1GcCqSUyyj3bNj/view?usp=sharing (accessed on 26 February 2021).

Acknowledgments: We thanks to Jana Urgosova and Ing. Danica Mihalova for technical assistance.

Conflicts of Interest: We declare no conflict of interest.

\section{References}

1. Guo, Q.; Wang, Y.; Xu, D.; Nossent, J.; Pavlos, N.J.; Xu, J. Rheumatoid arthritis: Pathological mechanisms and modern pharmacologic therapies. Bone Res. 2018, 6, 1-14. [CrossRef]

2. Chen, L.; Deng, H.; Cui, H.; Fang, J.; Zuo, Z.; Deng, J.; Li, Y.; Wang, X.; Zhao, L. Inflammatory responses and inflammation associated diseases in organs. Oncotarget 2018, 23, 7204-7218. [CrossRef] [PubMed]

3. Smolen, J.S.; Landewe, R.B.M.; Bijlsma, J.W.J.; Burmester, G.R.; Dougados, M.; Kerschbaumer, A.; McInnes, I.B.; Sepriano, A.; van Vollenhoven, R.F.; de Wit, M.; et al. EULAR recommendations for the management of rheumatoid arthritis with syntheticand biological disease-modifying antirheumatic drugs: 2019 Update. Ann. Rheum. Dis. 2020, 79, 685-699. [PubMed]

4. Kesharwani, D.; Paliwal, R.; Satapathy, T.; Das Paul, S. Rheumatiod arthritis: An updated overview of latest therapy and drug delivery. J. Pharmacopunct. 2019, 22, 210-224.

5. Hazlewood, G.S.; Barnabe, C.; Tomlinson, G.; Marshall, D.; Devoe, D.; Bombardier, C. Methotrexate monotherapy and methotrexate combination therapy with traditional and biologic disease modifying antirheumatic drugs for rheumatoid arthritis: Abridged Cochrane systematic review and network meta-analysis. BMJ 2016, 353, i1777. [CrossRef]

6. Salehi, B.; Martorell, M.; Arbiser, J.L.; Sureda, A.; Martins, N.; Maurya, P.K.; Sharifi-Rad, M.; Kumar, P.; Sharifi-Rad, J. Antioxidants: Positive or negative actors? Biomolecules 2018, 8, 124. [CrossRef] [PubMed]

7. Qiu, T.; Wu, D.; Yang, L.; Ye, H.; Wang, Q.; Cao, Z.; Tang, K. Exploring the mechanism of flavonoids through systematic bioinformatics analysis. Front. Pharmacol. 2018, 15, 918. [CrossRef] [PubMed]

8. Panche, A.N.; Diwan, A.D.; Chandra, S.R. Flavonoids: An overview. J. Nutr. Sci. 2016, 5, e47. [CrossRef]

9. Kumar, S.; Pandey, A.K. Chemistry and biological activities of flavonoids: An overview. Sci. World J. 2013, 2013, 162750. [CrossRef]

10. Mondal, S.; Rahaman, S.T. Flavonoids: A vital resource in healthcare and medicine. Pharm. Pharmacol. Int. J. 2020, 8, 91-104.

11. Bratkov, V.M.; Shkondrov, A.M.; Zdraveva, P.K.; Krasteva, I.N. Flavonoids from the Genus Astragalus: Phytochemistry and biological activity. Pharmacogn. Rev. 2016, 10, 11-32.

12. Maresca, M.; Micheli, L.; Cinci, L.; Bilia, A.R.; Ghelardini, C.; Di Cesare Mannelli, L. Pain relieving and protective effects of Astragalus hydroalcoholic extract in rat arthritis models. Pharm. Pharmacol. 2017, 69, 1858-1870. [CrossRef]

13. Alaniya, M.D.; Sutiashvili, M.G.; Kavtaradze, N.S.; Skhirtladze, A.V. Chemical constituents of Astragalus falcatus. Chem. Nat. Compd. 2017, 53, 1202-1203. [CrossRef]

14. Kemertelidze, E.; Alania, M.; Sagareishvili, T.; Shalashvili, K.; Kavtaradze, N. Medicinal preparations on the basis of vegetable phenolic compounds. Planta Med. 2009, 75, PD62. [CrossRef]

15. Kemertelidze, E.P.; Syrov, V.N.; Alaniya, M.D.; Kavtaradze, N.S.; Khushbaktova, Z.A. Chemical composition and pharmaco-logical activity of the leaves Pueraria hirsuta L. growing in Georgia. Pharm. Chem. J. 2008, 42, 340-343. [CrossRef]

16. Yahara, S.; Kohjyouma, M.; Kohoda, H. Flavonoid glycosides and saponins from Astragalus shikokianus. Phytochemistry 2000, 53, 469-471. [CrossRef]

17. Eom, S.H.; Jin, S.J.; Jeong, H.Y.; Song, Y.; Lim, Y.J.; Kim, J.I.; Lee, Y.H.; Kang, H. Kudzu Leaf extract suppresses the production of inducible nitric oxide synthase, cyclooxygenase-2, tumor necrosis factor-alpha, and Interleukin-6 via inhibition of JNK, TBK1 and STAT1 in inflammatory macrophages. Int. J. Mol. Sci. 2018, 19, 1536. [CrossRef] [PubMed]

18. Janeesh, P.A.; Abraham, A. Robinin modulates doxorubicin-induced cardiac apoptosis by TGF- $\beta 1$ signaling pathway in Sprague Dawley rats. Biomed. Pharmacother. 2014, 68, 989-998. [CrossRef] [PubMed]

19. Janeesh, P.A.; Sasikala, V.; Dhanya, C.R.; Abraham, A. Robinin modulates TLR/NF-kB signaling pathway in oxidized LDL induced human peripheral blood mono-nuclear cells. Int. Immunopharmacol. 2014, 18, 191-197. [CrossRef] [PubMed]

20. Choudhary, N.; Bhatt, L.K.; Prabhavalkar, K.S. Experimental animal models for rheumatoid arthritis. Immunopharmacol. Immunotoxicol. 2018, 40, 193-200. [CrossRef] [PubMed] 
21. Bevaart, L.; Vervoordeldonk, M.J.; Tak, P.P. Evaluation of therapeutic targets in animal models of arthritis: How does it relate torheumatoid arthritis? Arthritis Rheum. 2010, 62, 2192-2205. [CrossRef]

22. Bauerova, K.; Ponist, S.; Mihalova, D.; Drafi, F.; Kuncirova, V. Utilization of adjuvant arthritis model for evaluation of new approaches in rheumatoid arthritis therapy focused on regulation of immune processes and oxidative stress. Interdiscip. Toxicol. 2011, 4, 33-39. [CrossRef] [PubMed]

23. Ponist, S.; Gardi, C.; Paskova, L.; Svik, K.; Slovak, L.; Bilka, F.; Tedesco, I.; Bauerova, K.; Russo, L.G. Modulation of methotrexate efficacy by green tea polyphenols in rat adjuvant arthritis. PharmaNutrition 2020, 14, 100228. [CrossRef]

24. Orlowski, M.; Meister, A. The gamma-glutamyl cycle: A possible transport system for amino acids. Proc. Natl. Acad. Sci. USA 1970, 67, 1248-1255. [CrossRef] [PubMed]

25. Ondrejickova, O.; Ziegelhoeffer, A.; Gabauer, I.; Sotnikova, R.; Styk, J.; Gibala, P.; Sedlak, J.; Horakova, L. Evaluation of ischemiareperfusion injury by malondialdehyde, glutathione and gamma-glutamyltranspeptidase: Lack of specific localeffects in diverse parts of the dog heart following acute coronary occlusion. Cardioscience 1993, 4, 225-230. [PubMed]

26. Patil, K.R.; Mahajan, U.B.; Unger, B.S.; Goyal, S.N.; Belemkar, S.; Surana, S.J.; Ojha, S.; Patil, C.R. Animal models of inflammation for screening of anti-inflammatory drugs: Implications for the discovery and development of phytopharmaceuticals. Int. J. Mol. Sci. 2019, 20, 4367. [CrossRef]

27. Schinnerling, K.; Rosas, C.; Soto, L.; Thomas, R.; Aguillón, J.C. Humanized mouse models of rheumatoid arthritis for studies on immunopathogenesis and preclinical testing of cell-based therapies. Front. Immunol. 2019, 10, 203. [CrossRef]

28. Bauerova, K.; Acquaviva, A.; Ponist, S.; Gardi, C.; Vecchio, D.; Drafi, F.; Arezzini, B.; Bezakova, L.; Kuncirova, V.; Mihalova, D.; et al. Markers of inflammation and oxidative stress studied in adjuvant-induced arthritis in the rat on systemic and local level affected by pinosylvin and methotrexate and their combination. Autoimmunity 2015, 48, 46-56. [CrossRef] [PubMed]

29. Cronstein, B.N.; Aune, T.M. Methotrexate and its mechanisms of action in inflammatory arthritis. Nat. Rev. Rheumatol. 2020, 16, 145-154. [CrossRef] [PubMed]

30. Chan, E.S.L.; Cronstein, B.N. Mechanisms of action of methotrexate. Bull. Hosp. Jt. Dis. 2013, 71, S5-S8.

31. Bedoui, Y.; Guillot, X.; Sélambarom, J.; Guiraud, P.; Giry, C.; Jaffar-Bandjee, M.C.; Ralandison, S.; Gasque, P. Methotrexate an old drug with new tricks. Int. J. Mol. Sci. 2019, 20, 5023. [CrossRef] [PubMed]

32. Taylor, P.C.; Criado, A.B.; Mongey, A.B.; Avouac, J.; Marotte, H.; Mueller, R.B. How to get the most from methotrexate (MTX) treatment for your rheumatoid arthritis patient? MTX in the treat-to-target strategy. J. Clin. Med. 2019, 8, 515. [CrossRef] [PubMed]

33. Tsiklauri, L. Bioavailability of some biologically active compounds from Georgian flora. In Proceedings of the GeoHet-2011 2nd International Conference on Organic Chemistry: Advances in Heterocyclic Chemistry, Tbilisi, Georgia, 25-27 September 2011; p. 61.

34. Sokolova, V.E.; Vasil'chenko, E.A.; Izmailova, I.K. Ob anaboliziruiushchem deistvii flavonoidov [Anabolic action of flavonoids]. Farmakol. Toksikol. 1978, 41, 323-327. (In Bulgarian) [PubMed]

35. Vasil'chenko, E.A.; Sokolova, V.E. K voprosu o diureticheskom deřstvii robinina [Diuretic action of robinin]. Farmakol. Toksikol. 1973, 36, 97-100. (In Bulgarian) [PubMed]

36. Wang, M.; Li, H.; Wang, Y.; Hao, Y.; Huang, Y.; Wang, X.; Lu, Y.; Du, Y.; Fu, F.; Xin, W.; et al. Anti-rheumatic properties of gentiopicroside are associated with suppression of ROS-NF- $\mathrm{B}-\mathrm{NLRP3}$ axis in fibroblast-like synoviocytes and NF- $\mathrm{kB}$ pathway in adjuvant-induced arthritis. Front. Pharmacol. 2020, 11, 515. [CrossRef]

37. Bauerova, K.; Paulovicova, E.; Mihalova, D.; Drafi, F.; Strosova, M.; Mascia, C.; Biasi, F.; Rovensky, J.; Kucharska, J.; Gvozdjakova, A.; et al. Combined methotrexate and coenzyme Q10 therapy in adjuvant-induced arthritis evaluated using parameters of inflammation and oxidative stress. Acta Biochim. Pol. 2010, 57, 347-354. [CrossRef]

38. Bauerova, K.; Ponist, S.; Navarova, J.; Dubnickova, M.; Paulovicova, E.; Pajtinka, M.; Kogan, G.; Mihalova, D. Glucomannan in prevention of oxidative stress and inflammation occurring in adjuvant arthritis. Neuroendocrinol. Lett. 2008, 29, 691-696.

39. Bauerova, K.; Kucharska, J.; Ponist, S.; Gvozdjakova, A. Coenzyme Q10 supplementation in adjuvant arthritis (pre-clinical study). In Mitochondrial Medicine: Mitochondrial Metabolism, Diseases, Diagnosis and Therapy; Gvozdjakova, A., Ed.; Springer: Berlin, Germany, 2008; pp. 340-342.

40. Bauerova, K.; Paulovicova, E.; Mihalova, D.; Svik, K.; Ponist, S. Study of new ways of supplementary and combinatory therapy of rheumatoid arthritis with immunomodulators. Glucomannan and Imunoglukan in adjuvant arthritis. Toxicol. Ind. Health 2009, 25, 329-335. [CrossRef]

41. Tsiklauri, L.; Drafi, F.; Ponist, S.; Slovak, L.; Chrastina, M.; Svik, K.; Kemoklidze, Z.; Kemertelidze, E.; Bauerova, K. Study of anti-inflammatory activity of Fatsiphloginum ${ }^{\mathrm{TM}}$ (Fatsia japonica) and new purified triterpene-rich extract of saponins (PS-551) in experimental model of arthritis. Physiol. Res. 2019, 68, S75-S85. [CrossRef]

42. Ishizuka, Y.; Moriwaki, S.; Kawahara-Hanaoka, M.; Uemura, Y.; Serizawa, I.; Miyauchi, M.; Shibata, S.; Kanaya, T.; Takata, T.; Taniguchi, N.; et al. Treatment with anti-gamma-glutamyl transpeptidase antibody attenuates osteolysis in collagen-induced arthritis mice. J. Bone Miner. Res. 2007, 22, 1933-1942. [CrossRef]

43. Feketeova, L.; Jancova, P.; Moravcova, P.; Janegova, A.; Bauerova, K.; Ponist, S.; Mihalova, D.; Janega, P.; Babal, P. Effect of methotrexate on inflammatory cells redistribution in experimental adjuvant arthritis. Rheumatol. Int. 2012, 32, 3517-3523. [CrossRef] 
44. Rambabu, K.; Ansari, A.A.; Shaafie, I.A.; Chelvam, A.P.; Ziu, M. Gamma-glutamyltranspeptidase in synovial fluid, serum, and urine of patients with rheumatoid arthritis. Biochem. Med. Metab. Biol. 1990, 43, 183-192. [CrossRef]

45. Drafi, F.; Bauerova, K.; Kuncirova, V.; Ponist, S.; Mihalova, D.; Fedorova, T.; Harmatha, J.; Nosal, R. Pharmacological influence on processes of adjuvant arthritis: Effect of the combination of an antioxidant active substance with methotrexate. Interdiscip. Toxicol. 2012, 5, 84-91. [CrossRef]

46. Bauerova, K.; Ponist, S.; Ondrejickova, O.; Komendova, D.; Mihalova, D. Association between tissue gamma-glutamyl-transferase and clinical markers of adjuvant arthritisin Lewis rats. Neuro Endocrinol. Lett. 2006, 27, 172-175. [PubMed]

47. Chen, Q.J.; Niu, X.H.; Li, N.N. Exploring the natural chemiome to target interleukin-6 receptor (IL-6R) cytokines: An atomic scale investigation for novel rheumatoid arthritis drug discovery. Braz. J. Pharm. Sci. 2017, 53, e17256. [CrossRef]

48. Neumann, E.; Lefèvre, S.; Zimmermann, B.; Gay, S.; Müller-Ladner, U. Rheumatoid arthritis progression mediated by activated synovial fibroblasts. Trends Mol. Med. 2010, 16, 458-468. [CrossRef] [PubMed]

49. Arleevskaya, M.I.; Larionova, R.V.; Brooks, W.H.; Bettacchioli, E.; Renaudineau, Y. Toll-like receptors, infections, and rheumatoid arthritis. Clin. Rev. Allerg. Immunol. 2020, 58, 172-181. [CrossRef]

50. Lee, S.Y.; Yoon, B.Y.; Kim, J.I.; Heo, Y.M.; Woo, Y.J.; Park, S.H.; Kim, H.Y.; Kim, S.I.; Cho, M.L. Interleukin-17 increases the expression of Toll-like receptor 3 via the STAT3 pathway in rheumatoid arthritis fibroblast-like synoviocytes. Immunology 2014, 141, 353-361. [CrossRef] [PubMed]

51. Samarpita, S.; Kim, J.Y.; Rasool, M.K.; Kim, K.S. Investigation of toll-like receptor (TLR) 4 inhibitor TAK-242 as a new potential anti-rheumatoid arthritis drug. Arthritis Res. Ther. 2020, 22, 16. [CrossRef]

52. Kugyelka, R.; Kohl, Z.; Olasz, K.; Mikecz, K.; Rauch, T.A.; Glant, T.T.; Boldizsar, F. Enigma of IL-17 and Th17 cells in rheumatoid arthritis and in autoimmune animal models of arthritis. Mediat. Inflamm. 2016, 2016, 6145810. [CrossRef]

53. Nasef, N.; Elnagdy, M.; Younis, W.; Badr, R.; El-bussiouni, S.; Akef, A.; Rashwan, M. T helper 17 cells and interleukin-17 in patients with rheumatoid arthritis. Int. J. Clin. Rheumatol. 2019, 14, 113-119.

54. Robert, M.; Miossec, P. IL-17 in rheumatoid arthritis and precision medicine: From synovitis expression to circulating bioactive levels. Front. Med. 2019, 5, 364. [CrossRef]

55. Hu, D.; Tjon, E.C.; Andersson, K.M.; Molica, G.M.; Pham, M.C.; Healy, B.; Murugaiyan, G.; Pochet, N.; Kuchroo, V.K.; Bokarewa, M.I.; et al. Aberrant expression of USF2 in refractory rheumatoid arthritis and its regulation of proinflammatory cytokines in Th17 cells. Proc. Natl. Acad. Sci. USA 2020, 117, 30639-30648. [CrossRef]

56. Dai, Q.; Li, Y.; Wang, M.; Li, Y.; Li, J. TIR2 and TIR4 are involved in the treatment of rheumatoid arthritis synovial fibroblasts with a medicated serum of asarinin through inhibition of Th1/Th17 cytokines. Exp. Ther. Med. 2020, 19, 3009-3016. [CrossRef] [PubMed]

57. Codreanu, C.; Popescu, C.C.; Mogoșan, C.D.; Enache, L.; Manda, G.; Berghea, F.; Groșeanu, L.; Predețeanu, D. Targeting Interleukin 17 in the treatment of rheumatoid arthritis. Farmacia 2018, 66, 390-398. [CrossRef]

58. Friedman, B.; Cronstein, B. Methotrexate mechanism in treatment of rheumatoid arthritis. Jt. Bone Spine 2019, 86, 301-307. [CrossRef]

59. Li, Y.; Jiang, L.; Zhang, S.; Yin, L.; Ma, L.; He, D.; Shen, J. Methotrexate attenuates the Th17/IL-17 levels in peripheral blood mononuclear cells from healthy individuals and RA patients. Rheumatol. Int. 2012, 32, 2415-2422. [CrossRef] [PubMed]

60. Luo, Q.; Lin, L.; Li, J.; Zhu, H.; He, Y.; Liu, Y.; Zeng, K.; Zhang, X. Effects of methotrexate on the expression of Toll like receptor (TLR)2 and TLR4 in human peripheral blood CD14+ mononuclear cells from patients with psoriasis vulgaris. Chin. J. Dermatol. 2009, 42, 760-762.

61. Toh, M.L.; Gonzales, G.; Koenders, M.I.; Tournadre, A.; Boyle, D.; Lubberts, E.; Zhou, Y.; Firestein, G.S.; van den Berg, W.B.; Miossec, P. Role of interleukin 17 in arthritis chronicity through survival of synoviocytes via regulation of synoviolin expression. PLoS ONE 2010, 5, e13416. [CrossRef]

62. El-Ghazaly, M.A.; Fadel, N.A.; Abdel-Naby, D.H.; El-Rehim, H.A.A.; Zaki, H.F.; Kenawy, S.A. Potential anti-inflammatory action of resveratrol and piperine in adjuvant-induced arthritis: Effect on pro-inflammatory cytokines and oxidative stress biomarkers. Egypt. Rheumatol. 2020, 42, 71-77. [CrossRef]

63. Khan, M.A.; Sarwar, A.H.; Rahat, R.; Ahmed, R.S.; Umar, S. Stigmasterol protects rats from collagen induced arthritis by inhibiting proinflammatory cytokines. Int. Immunopharmacol. 2020, 85, 106642. [CrossRef] [PubMed]

64. Zhang, H.; Yin, L.; Lu, M.; Wang, J.; Li, Y.T.; Gao, W.L.; Yin, Z.S. Evodiamine attenuates adjuvant-induced arthritis in rats by inhibiting synovial inflammation and restoring the Th17/Treg balance. J. Pharm. Pharmacol. 2020, 72, 798-806. [CrossRef]

65. Griffiths, L.A.; Smith, G.E. Metabolism of apigenin and related compounds in the rat. Metabolite formation in vivo and by the intestinal microflora in vitro. Biochem. J. 1972, 128, 901-911. [CrossRef] [PubMed]

66. Najmanova, I.; Pourova, J.; Mladenka, P. A mixture of phenolic metabolites of quercetin can decrease elevated blood pressure of spontaneously hypertensive rats even in low doses. Nutrients 2020, 12, 213. [CrossRef]

67. Lee, J.H.; Kim, G.H. Evaluation of antioxidant and inhibitory activities for different subclasses flavonoids on enzymes for rheumatoid arthritis. J. Food Sci. 2010, 75, H212-H217. [CrossRef]

68. Tang, X.L.; Liu, J.; Dong, W.; Li, P.; Li, L.; Hou, J.C.; Zheng, Y.Q.; Lin, C.R.; Ren, J.G. Protective effect of kaempferol on LPS plus ATP-induced inflammatory response in cardiac fibroblasts. Inflammation 2015, 38, 94-101. [CrossRef] 